\title{
An Interactive Consensus Model for Group Decision-Making with Incomplete Multi-Granular 2-Tuple Fuzzy Linguistic Preference Relations
}

\author{
Yongming Song $\mathbb{C}^{1}$ and Feng Yuan ${ }^{2,3}$ \\ ${ }^{1}$ School of Business Administration, Shandong Technology and Business University, Yantai 264005, China \\ ${ }^{2}$ School of Information Engineering, Shandong Management University, Jinan 250357, China \\ ${ }^{3}$ Key Laboratory of TCM Data Cloud Service in Universities of Shandong, Shandong Management University, Jinan 250357, China \\ Correspondence should be addressed to Yongming Song; xinshiji7819@163.com
}

Received 6 May 2018; Revised 4 August 2018; Accepted 5 August 2018; Published 16 August 2018

Academic Editor: Luis Martínez

Copyright (c) 2018 Yongming Song and Feng Yuan. This is an open access article distributed under the Creative Commons Attribution License, which permits unrestricted use, distribution, and reproduction in any medium, provided the original work is properly cited.

\begin{abstract}
As a result of the heterogeneity of decision-makers, it is more suitable to use multi-granular linguistic information to express assessing information over alternatives for decision-makers. Decision-makers may only provide partial preference information as the limitation of knowledge over the alternatives. Thus, the incomplete multi-granular 2-tuple fuzzy linguistic preference relations (IMGFLPRs) can be applied to manage the GDM problems in complex environments. In this paper, we propose a novel group decision-making (GDM) model based on mathematical programming with IMGFLPRs. It is more important that the proposed mathematical programming can directly deal with IMGFLPRs and does not need to be converted into a uniform form. By this means, we construct a consensus reaching process based on IMGFLPRs, considering simultaneously dynamic adjustment of experts' weight. Finally, an emergency plan selection problem is solved by the proposed model, which shows the result of GDM is effectiveness.
\end{abstract}

\section{Introduction}

With the development of society, decision-making environments are more and more complex and uncertain. Thus, group decision-making (GDM) is put forward and widely applied to integrate individual preference information on alternatives from multiple decision-makers. In some cases, it is difficult for decision-makers (DMs) to express their assessments about alternatives by exact numerical values. Therefore, utilizing linguistic information proposed by Zadeh [1] to represent their assessments may be more appropriate way for DMs. Besides, for linguistic information-based GDM problems, multiple DMs with different level of cognitive competence and knowledge may engage in the decisionmaking process, which usually implies the necessity of multiple linguistic scales (multi-granular linguistic term sets) to express properly different knowledge for different DMs [2]. Multi-granular fuzzy linguistic-based models have been frequently developed in GDM [2-9].
Preference relation is a useful tool for DMs to provide their preferences information on alternatives, for example multiplicative preference relation [10], fuzzy preference relation (FPR) [11] and linguistic preference relation (LPR) [12], etc. Furthermore, it is well understood in the field of decisionmaking that an expert might not possess adequate levels of knowledge or information to address a given decisionmaking problem [13], then incomplete evaluations can occur in the complex environment. A number of incomplete preference relations have been developed in recent years [14-17].

Consensus is a significant issue widely considered in GDM problems. The consensus assures the unity of opinions of DMs, which makes the result of decision-making accepted by most DMs. A number of methods with a range of preference relations have been proposed to manage the GDM based on consensus [2, 4, 8, 18-27]. Herrera-Viedma et al. [2] established an information feedback mechanism to provide advices with experts to adjust in order to come true a solution 
with high consistency and consensus levels. Wu and $\mathrm{Xu}$ [19] proposed a GDM model based on automatically adjusting consistency as well as consensus to achieve the acceptable predefined level. Liao et al. [24] proposed an improved consensus reaching mechanism in GDM based on multiplicative transitivity of intuitionistic fuzzy preference relation. Although a large number of models have already been proposed to manage GDM problems based on incomplete multi-granular 2-tuple fuzzy linguistic preference relations (IMGFLPRs) [4, 8], there are some drawbacks to the existing research. There is no consensus reaching process in both methods described above $[4,8]$, which makes the result of decision-making would not be accepted by most decision-makers. Therefore, an important goal of this paper is to establish a consensus reaching process to deal with IMGFLPRs in group decisionmaking. Besides, the previous studies $[4,8]$ need estimate unknown elements, which becomes burden on DMs due to the complexity of calculation.

In light of the gaps identified above, we are devoted to presenting a consensus model with IMGFLPRs. First, a mathematical programming is established to get directly individual priority weight vector based on an equivalence theorem between FLPR and FPR. Following this, the collective preference vector is obtained by means of IOWA operator. After that, a consensus reaching algorithm is constructed based on direct consensus framework to obtain the collective priority weight vector with satisfactory level of consensus. In the process of consensus, the experts' weight values are dynamically adjusted according the quality of information provided.

The rest of this paper is organized as follows. Section 2 reviews some basic knowledge of linguistic information and 2-tuple FLPR. In Section 3, we propose a novel GDM model with IMGFLPs. In Section 4, a problem of emergency decision is resolved by the proposed model. Section 5 carries out a comparison of our suggested method with previous related researches and summarizes the main contributions of this paper. Some concluding remarks are given in Section 6 .

\section{Preliminaries}

In this section, we review the related knowledge about linguistic information, multi-granular linguistic information, two-tuple FLPR, and additive consistency of FLPR.

2.1. Linguistic Information. To facilitate the assessment using linguistic for DMs, a linguistic term set should be determined beforehand. The widely used linguistic term set has following characteristics: (a) the odd value with granularity; (b) its membership functions being symmetrical and uniformly distributed; (c) the midterm of linguistic term set representing "indifference", with the remainder of the linguistic terms symmetrically and uniformly being placed on either side of it. Let $S=\left\{s_{0}, s_{1}, \cdots, s_{g}\right\}$ be a linguistic term set with odd granularity and $g+1$ is the granularity of the linguisticS. Moreover, the term set $S$ should satisfy the following features [28]: (1) a negation operator: $\operatorname{Neg}\left(s_{i}\right)=s_{g-i}$; (2) an order: $s_{i} \geq s_{j}$, if $i \geq j$.
The 2-tuple linguistic expressive model was presented [28] and it may improve the accuracy of linguistic computational models.

Definition 1 (see [28]). Suppose $\beta \in[0, g]$ is the result of a symbolic aggregation operation in a linguistic term set $S=$ $\left\{s_{0}, s_{1}, \cdots, s_{g}\right\}$. Then, the equivalent information to $\beta$ in the 2-tuple is obtained by the following function:

$$
\begin{aligned}
\Delta:[0, g] & \longrightarrow S \times[-0.5,0.5) \\
\Delta(\beta) & = \begin{cases}s_{i} & i=\operatorname{round}(\beta) \\
\alpha=\beta-i & \alpha \in[-0.5,0.5),\end{cases}
\end{aligned}
$$

where round is the rounding operation.

Definition 2 (see [28]). Suppose $S=\left\{s_{0}, s_{1}, \cdots, s_{g}\right\}$ is a linguistic term set and $\left(s_{i}, \alpha\right)$ be a 2 -tuple, then there exists a function $\Delta^{-1}$ which transforms a 2-tuple into its equivalent numerical value $\beta \in[0, g]$. The function $\Delta^{-1}$ is defined as follows:

$$
\begin{gathered}
\Delta^{-1}: S \times[-0.5,0.5) \longrightarrow[0, g] \\
\Delta^{-1}\left(s_{i}, \alpha\right)=i+\alpha
\end{gathered}
$$

According to Definitions 1 and 2, a linguistic label can be transformed into a two-tuple linguistic by adding a zero as a symbolic translation, i.e., $\Delta\left(s_{i}\right)=\left(s_{i}, 0\right)$.

In addition, the comparison of two-tuple linguistic was given in [28]. For two 2-tuples: $\left(s_{i}, \alpha\right)$ and $\left(s_{j}, \beta\right)$, then

(1) if $i<j$, then $\left(s_{i}, \alpha\right)$ is smaller than $\left(s_{j}, \beta\right)$;

(2) if $i=j$, then
(a) if $\alpha=\beta$, then $\left(s_{i}, \alpha\right)$ and $\left(s_{j}, \beta\right)$ represent the same information;
(b) if $\alpha<\beta$, then $\left(s_{i}, \alpha\right)$ is smaller than $\left(s_{j}, \beta\right)$.

2.2. Multi-Granular Linguistic Information. When multiple DMs are taking part in a decision-making concern, different experts showcase different levels of uncertainty regarding the items. It is quite natural that linguistic term sets with different cardinality could be used to provide their preferences over the alternatives. A decision-maker having the capacity to deliver precise information puts to use a finer granularity linguistic term set. Contrarily, the decision-maker is likely to select a coarse granularity linguistic term set [2].

In this paper, we handle GDM problems based on multigranular linguistic, i.e., GDM problems where the experts $e_{k}(k=1,2, \cdots, m)$ may express their linguistic preference relations $P_{k}=\left(p_{i j}^{(k)}\right)_{n \times n}$ on the set of alternatives $X=$ $\left\{x_{1}, x_{2}, \cdots, x_{n}\right\}$ based on given multi-granular linguistic term sets. Let $S^{g^{(1)}}, S^{g(2)}, \cdots, S^{g(r)}$ be the linguistic term sets to be used by the DMs, where $S^{g^{(h)}}=\left\{s_{0}^{g(h)}, s_{1}^{g(h)}, \cdots, s_{g(h)-1}^{g(h)}\right\}$ is a linguistic term set with a granularity of $g(h), h \in\{1,2, \cdots, r\}$. Therefore, $p_{i j}^{k} \in S^{g(h)}$ represents the preference of alternative $x_{i}$ over alternative $x_{j}$ for the expert $e_{k}$ based on the linguistic term set $S^{g(h)}$. 


\subsection{Two-Tuple FLPR and Additive Consistency of FLPR}

Definition 3 (see [29]). $P=\left(p_{i j}\right)_{n \times n}$ is called a 2-tuple FLPR; if the following conditions hold for all $i, j$,

$$
\begin{aligned}
\Delta^{-1}\left(p_{i j}\right)+\Delta^{-1}\left(p_{j i}\right) & =g, \\
\Delta^{-1}\left(p_{i i}\right) & =\frac{g}{2} .
\end{aligned}
$$

where $S=\left\{s_{0}, s_{1}, \cdots, s_{g}\right\}$ is a given linguistic term set.

Moreover, Alonso et al. [29] established the additive consistency of 2-tuple FLPR as follows:

$$
\begin{aligned}
& \Delta^{-1}\left(p_{i j}\right)=\Delta^{-1}\left(p_{i k}\right)+\Delta^{-1}\left(p_{k j}\right)-\Delta^{-1}\left(s_{g / 2}, 0\right), \\
& \forall i, j, k \in\{1,2, \cdots, n\}
\end{aligned}
$$

\section{A Group Decision-Making Model with Incomplete Multi-Granular 2-Tuple FLPRs}

In this section, a group decision-making model with IMGPLPRs is proposed based on mathematical programming. First, a mathematical programming is established to deal with IMGFLPRs and obtain the priority weight vector; second, I-IOWA operator of 2-tuple FLPR is introduced to obtain collective priority weight vector in Section 3.2. Finally, a consensus reaching process algorithm is established with IMGFLPRs in Section 3.3.

3.1. A Mathematical Programming Model to Deal with IMGFLPR. In what follows, an equivalence property of additive consistency between a 2-tuple FLPR and its corresponding FPR [30] is reviewed.

Suppose $P=\left(p_{i j}\right)_{n \times n}$ is a 2-tuple FLPR and $S=\left\{s_{0}\right.$, $\left.s_{1}, \cdots, s_{g}\right\}$ is a linguistic scale set. Let $r_{i j}=\Delta^{-1}\left(p_{i j}\right) / g$, then we get $r_{i j}, r_{j i} \in[0,1]$ and $r_{i j}+r_{j i}=\Delta^{-1}\left(p_{i j}\right) / g+\Delta^{-1}\left(p_{j i}\right) / g=$ 1. Hence, $R=\left(r_{i j}\right)_{n \times n}$ is an FPR. Here, $R=\left(r_{i j}\right)_{n \times n}$ is called the FPR matrix corresponding to the 2-tuple FLPR $P=\left(p_{i j}\right)_{n \times n}$. In the following, we review the equivalence property of consistency between $P=\left(p_{i j}\right)_{n \times n}$ and $R=\left(r_{i j}\right)_{n \times n}$.

Theorem 4 (see [30]). $P=\left(p_{i j}\right)_{n \times n}$ is an additive consistent 2-tuple FLPR $\Longleftrightarrow R=\left(r_{i j}\right)_{n \times n}$ is an additive consistent FPR

Remark 5. From the Theorem 4, it can be seen that the additive consistent 2 -tuple FLPR $P=\left(p_{i j}\right)_{n \times n}$ can be obtained by its corresponding additive consistent FPR $R=\left(r_{i j}\right)_{n \times n}$.

Based on the Theorem 4, a mathematical programming is established to deal with IMGFLPR. Suppose $P=\left(p_{i j}\right)_{n \times n}$ is an additive consistent 2 -tuple FLPR and a normalized weight vector is $\omega=\left(\omega_{1}, \omega_{2}, \cdots, \omega_{n}\right)^{T}$. Based on the relationship between $\omega_{i}, \omega_{j}$, and $r_{i j}$ proposed by Xu et al. [31,32], we can obtain

$$
\frac{\Delta^{-1}\left(p_{i j}\right)}{g}=0.5+\frac{n-1}{2}\left(\omega_{i}-\omega_{j}\right)
$$

Equation (5) can be transformed to

$$
\Delta^{-1}\left(p_{i j}\right)=\frac{g}{2}+\frac{g(n-1)}{2}\left(\omega_{i}-\omega_{j}\right),
$$

If a 2-tuple FLPR is not additive consistency, then there does not exist a priority vector that satisfies (6). In practice, it is difficult to satisfy the perfect consistency. Then, the "Soft" consistency was proposed to express approximate consistency $[33,34]$. Let $L_{i j}(\omega)=g / 2+(g(n-1) / 2)\left(\omega_{i}-\omega_{j}\right)-$ $\Delta^{-1}\left(p_{i j}\right)$; if $L_{i j}(\omega)=0$, then we say that the satisfaction degree of the priorities equals one. Otherwise, the satisfaction degree should reduce for some deviation. In order to get the optimal weight vector, the following mathematical programming is established:

$$
\begin{array}{ll}
\min & \varepsilon_{i j}=\left|\frac{g}{2}+\frac{g(n-1)}{2}\left(\omega_{i}-\omega_{j}\right)-\Delta^{-1}\left(p_{i j}\right)\right| \\
\text { s.t. } & \sum_{i=1}^{n} \omega_{i}=1, \quad \omega_{i} \geq 0 \\
& i, j=1,2, \cdots, n,
\end{array}
$$

For the sake of simplifying model (7), we present the following Theorem 6 .

Theorem 6. For model (7), the following relationship is established:

$$
\begin{aligned}
\mid \frac{g}{2} & +\frac{g(n-1)}{2}\left(\omega_{j}-\omega_{i}\right)-\Delta^{-1}\left(p_{j i}\right) \mid \\
& =\left|\frac{g}{2}+\frac{g(n-1)}{2}\left(\omega_{i}-\omega_{j}\right)-\Delta^{-1}\left(p_{i j}\right)\right| .
\end{aligned}
$$

Proof. Based on the properties of the FLPR, we have

$$
\Delta^{-1}\left(p_{j i}\right)=g-\Delta^{-1}\left(p_{i j}\right)
$$

Then,

$$
\begin{aligned}
\mid \frac{g}{2} & +\frac{g(n-1)}{2}\left(\omega_{j}-\omega_{i}\right)-\Delta^{-1}\left(p_{j i}\right) \mid \\
& =\left|\frac{g}{2}+\frac{g(n-1)}{2}\left(\omega_{j}-\omega_{i}\right)-\left(g-\Delta^{-1}\left(p_{j i}\right)\right)\right| \\
& =\left|\frac{g}{2}+\frac{g(n-1)}{2}\left(\omega_{j}-\omega_{i}\right)-g+\Delta^{-1}\left(p_{j i}\right)\right| \\
& =\left|\frac{g(n-1)}{2}\left(\omega_{j}-\omega_{i}\right)-\frac{g}{2}+\Delta^{-1}\left(p_{j i}\right)\right| \\
& =\left|\frac{g}{2}+\frac{g(n-1)}{2}\left(\omega_{i}-\omega_{j}\right)-\Delta^{-1}\left(p_{i j}\right)\right|
\end{aligned}
$$

which completes the proof of Theorem 6 .

Based on Theorem 6, model (7) can be reduced to model (11):

$$
\begin{array}{ll}
\min & \varepsilon_{i j}=\left|\frac{g}{2}+\frac{g(n-1)}{2}\left(\omega_{i}-\omega_{j}\right)-\Delta^{-1}\left(p_{i j}\right)\right| \\
\text { s.t. } & \sum_{i=1}^{n} \omega_{i}=1, \quad \omega_{i} \geq 0
\end{array}
$$




$$
i, j=1,2, \cdots, n, \quad i<j
$$

Moreover, model (11) can be transformed into the following mathematical programming:

$$
\begin{aligned}
& \min \quad f=\sum_{i=1}^{n-1} \sum_{j=2, j>i}^{n}\left(t_{i j} d_{i j}^{+}+m_{i j} d_{i j}^{-}\right) \\
& \text {s.t. } \quad \frac{g}{2}+\frac{g(n-1)}{2}\left(\omega_{i}-\omega_{j}\right)-\Delta^{-1}\left(p_{i j}\right)-t_{i j} d_{i j}^{+} \\
& \quad+m_{i j} d_{i j}^{-}=0 \\
& d_{i j}^{+}, d_{i j}^{-} \geq 0 \\
& \sum_{i=1}^{n} \omega_{i}=1, \quad \omega_{i} \geq 0 \\
& i, j=1,2, \cdots, n, \quad i<j,
\end{aligned}
$$

where $d_{i j}^{+}$and $d_{i j}^{-}$are the positive and negative deviations with respect to the goal $\varepsilon_{i j}$, respectively. $t_{i j}$ and $m_{i j}$ are the weights corresponding to $d_{i j}^{+}$and $d_{i j}^{-}$, respectively.

In general, we assume that all goals $\varepsilon_{i j}(i, j=1,2, \cdots, n$, $i<j)$ are fair and then $t_{i j}=m_{i j}=1(i, j=1,2, \cdots, n, i<j)$. Thus, model (12) can be translated into the following model:

$$
\begin{array}{ll}
\min & f=\sum_{i=1}^{n-1} \sum_{j=2, j>i}^{n}\left(d_{i j}^{+}+d_{i j}^{-}\right) \\
\text {s.t. } & \frac{g}{2}+\frac{g(n-1)}{2}\left(\omega_{i}-\omega_{j}\right)-\Delta^{-1}\left(p_{i j}\right)-d_{i j}^{+}+d_{i j}^{-} \\
& =0 \\
& d_{i j}^{+}, d_{i j}^{-} \geq 0 \\
& \sum_{i=1}^{n} \omega_{i}=1, \quad \omega_{i} \geq 0 \\
& i, j=1,2, \cdots, n, \quad i<j,
\end{array}
$$

Based on positive $d_{i j}^{+}$and negative deviation $d_{i j}^{-}$in model (13), the consistency level of $P$ is defined as

$$
c l(P)=1-\frac{2 \sum_{i=1}^{n-1} \sum_{j=2, j>i}^{n}\left(d_{i j}^{+}+d_{i j}^{-}\right)}{g n(n-1)}
$$

Remark 7. Based on the above discussion, it is deserved to note that model (13) could serve a dual function: on the one hand, it could directly deal with incomplete multi-granular 2tuple FLPR with different linguistic granular, and on the other hand it might also get the individual consistency level $c l(P)$.

In what follows, we apply model (13) to deal with Example 8.
Example 8. Suppose an incomplete FLPR $P$ as follows:

$$
P=\left[\begin{array}{cccc}
\left(s_{3}, 0\right) & \left(s_{2}, 0\right) & x & \left(s_{2}, 0\right) \\
\left(s_{4}, 0\right) & \left(s_{3}, 0\right) & \left(s_{1}, 0\right) & x \\
x & \left(s_{5}, 0\right) & \left(s_{3}, 0\right) & \left(s_{4}, 0\right) \\
\left(s_{4}, 0\right) & x & \left(s_{2}, 0\right) & \left(s_{3}, 0\right)
\end{array}\right]
$$

where $S^{7}=\left\{s_{0}^{7}=\right.$ very poor, $s_{1}^{7}=$ poor, $s_{2}^{7}=$ slightly poor, $s_{3}^{7}=$ fair, $s_{4}^{7}=$ slightly good, $s_{5}^{7}=\operatorname{good}, s_{6}^{7}=$ very good $\}$.

According to model (13), we obtain the following mathematical programming:

$$
\begin{array}{ll}
\min & f \\
& =d_{12}^{+}+d_{12}^{-}+d_{14}^{+}+d_{14}^{-}+d_{23}^{+}+d_{23}^{-}+d_{34}^{+} \\
& +d_{34}^{-} \\
\text {s.t. } \quad & 9 \omega_{1}-9 \omega_{2}-d_{12}^{+}+d_{12}^{-}=-1, \\
& 9 \omega_{1}-9 \omega_{4}-d_{14}^{+}+d_{14}^{-}=-1, \\
& 9 \omega_{2}-9 \omega_{3}-d_{23}^{+}+d_{23}^{-}=-2, \\
& 9 \omega_{3}-9 \omega_{4}-d_{34}^{+}+d_{34}^{-}=1, \\
& d_{12}^{+}, d_{12}^{-}, d_{14}^{+}, d_{14}^{-}, d_{23}^{+}, d_{23}^{-}, d_{34}^{+}, d_{34}^{-} \geq 0, \\
& \sum_{i=1}^{4} \omega_{i}=1, \quad \omega_{i} \geq 0, i=1,2,3,4
\end{array}
$$

By means of MATLAB, we can obtain $\omega=(0.1251$, $0.2082,0.4028,0.2638)^{T}$ and $\operatorname{cl}(P)=0.9722$ based on $d_{12}^{+}=$ $0.2519, d_{14}^{-}=0.248, d_{23}^{+}=0.2486, d_{34}^{+}=0.2516, d_{12}^{-}=d_{14}^{+}=$ $d_{23}^{-}=d_{34}^{-}=0$.

3.2. IOWA Operator Based on Consistency Level. In order to obtain collective priority weight vector, the IOWA operator based on consistency level [35] is used.

Individual priority weight vectors $\omega^{(k)}=\left(\omega_{1}^{(k)}, \omega_{2}^{(k)}\right.$, $\left.\cdots, \omega_{n}^{(k)}\right)(k=1,2, \cdots, m)$ can be combined into collective priority weight vector $\omega^{(c)}=\left(\omega_{1}^{(c)}, \omega_{2}^{(c)}, \cdots, \omega_{n}^{(c)}\right)$ according to IOWA operator based on consistency level:

$$
\begin{aligned}
\omega_{i}^{(c)} & =I O W A_{Q^{c}}\left(\omega_{i}^{(1)}, \omega_{i}^{(2)}, \cdots, \omega_{i}^{(m)}\right) \\
& =\Phi_{\omega}\left(\left\langle c l^{1}, \omega_{i}^{(1)}\right\rangle,\left\langle c l^{2}, \omega_{i}^{(2)}\right\rangle, \cdots,\left\langle c l^{m}, \omega_{i}^{(m)}\right\rangle\right) \\
& =\sum_{\tau=1}^{m} u_{\tau} \omega_{i}^{(\tau)} \\
u_{\tau} & =Q\left(\frac{\sum_{k=1}^{\tau} c l^{\sigma(\tau)}}{T}\right)-Q\left(\frac{\sum_{k=1}^{\tau-1} c l^{\sigma(\tau)}}{T}\right)
\end{aligned}
$$

where $T=\sum_{k=1}^{m} c l^{\sigma(k)}$ and $c l^{\sigma(k)}$ is the $k t h$ largest value $\operatorname{in}\left\{c l^{1}, c l^{2}, \cdots, c l^{m}\right\}$. 
Input: Individual FLPRs $P_{1}, P_{2}, \cdots, P_{m}$, the experts' weight vector $u=\left(u_{1}, u_{2}, \cdots, u_{m}\right)^{T}$, the thresholds $\overline{G C I}$ and the maximum iterations $t_{\max } \geq 1$.

Output: Adjusted FLPRs $P_{1}^{(t)}, P_{2}^{(t)}, \cdots, P_{m}^{(t)}, \operatorname{GCI}\left(P_{k}^{(t)}\right)(k=1,2, \cdots, m), P_{c}^{(t)}$ and the iterations $t$.

Step 1: Set $t=0$ and $P_{k}^{(0)}=P_{k}(k=1,2, \cdots, m)$.

Step 2: Obtain individual priority weight vector $\omega_{1}^{(t)}, \omega_{2}^{(t)}, \cdots, \omega_{m}^{(t)}$ using the model (13) and then get the experts' weight vector $u^{(t)}=\left(u_{1}^{(t)}, u_{2}^{(t)}, \cdots, u_{m}^{(t)}\right)^{T}$ according to Eq. (18).

Step 3: Compute the collective priority weight vector $\omega_{c}^{(t)}$ corresponding to $\omega_{1}^{(t)}, \omega_{2}^{(t)}, \cdots, \omega_{m}^{(t)}$ by means of IOWA operator.

Step 4: Count the $G C I\left(P_{k}^{(t)}\right)(k=1,2, \cdots, m)$ according to Eq. (19). If $G C I\left(P_{k}^{(t)}\right) \geq$

$\overline{G C I}(k=1,2, \cdots, m)$ or $t \geq t_{\max }$, go to Step 6; Or else, find the FLPR $P_{k}^{(t)}$ that satisfies $G C I\left(P_{k}^{(t)}\right)<\overline{G C I}$ and proceed to Step 5 .

Step 5: Ascertain the position of the elements $d_{i_{\tau} j_{\tau}, k}^{(t)}$ for expert $e_{k}$ satisfying $G C I\left(P_{k}^{(t)}\right)<$ $\overline{G C I}$, where $d_{i_{\tau} j_{\tau}, k}^{(t)}=\max _{(i, j)}\left|\Delta^{-1}\left(p_{i j, k}^{(t)}\right)-\Delta^{-1}\left(p_{i j, \mathrm{c}}^{(t)}\right)\right|$, and then adjust expert $e_{k}$ 's FLPR according to Eq. (20).

Set $t=t+1$ and go to Step 2 .

Step 6: Let $\overline{P_{k}}=P_{k}^{(t)}(k=1,2, \cdots, m)$ and $\omega^{*}=\omega_{c}^{(t)}$. Output $\overline{P_{1}}, \overline{P_{2}}, \cdots, \overline{P_{m}}$, $\operatorname{GCI}\left(\overline{P_{k}}\right)(k=1,2, \cdots, m), \omega^{*}=\omega_{c}^{(t)}$ and the iterations $t$.

Algorithm 1

3.3. Consensus Reaching Process Algorithm. As shown in $[36,37]$, the consensus reaching process algorithm based on direct approach has two desirable properties: (1) it can avoid internal inconsistency with multi-granular 2-tuple FLPRs, and (2) it is satisfied with the Pareto principle in social choice theory. Inspired by the direct approach $[36,37]$, we adopt the direct approach to manage consensus reaching process in this study.

\subsubsection{Consensus Index}

Definition 9. Let $\omega^{(k)}$ and $\omega^{(c)}$ be shown earlier. The group consensus index (GCI) for $e_{k}$ is defined as follows:

$$
G C I\left(e_{k}\right)=1-\sqrt{\frac{1}{n} \sum_{i=1}^{n}\left(\omega_{i}^{(k)}-\omega_{i}^{(c)}\right)^{2}},
$$

If $\operatorname{GCI}\left(e_{k}\right)=1(k=1,2, \cdots, m)$, all decision-makers agree with the group; otherwise, the larger $\operatorname{GCI}\left(e_{k}\right)$ is, the higher the consensus index is.

3.3.2. Group Consensus Reaching Process. The goal of the feedback adjustment is to provide adjustment advice to help DMs improve the consensus level. In this study, an interaction feedback adjustment strategy is proposed based on the personal original preference information and the adjusted group preference information to regulate the personal preference information; that is to say, the DMs modify his/her preference to improve the group consensus level. According to the different granular linguistic structure, the interactive feedback adjustment mechanism should be considered.
For $e_{k} \in S^{g(h)}=\left\{s_{0}^{g(h)}, s_{1}^{g(h)}, \cdots, s_{g(h)-1}^{g(h)}\right\}$, the adjustment proposals are given as follows:

$$
\begin{aligned}
& \overline{p_{i j, k}} \in\left[\min \left\{p_{i j, k}, p_{i j, c}^{g(h)}\right\}, \max \left\{p_{i j, k}, p_{i j, c}^{g(h)}\right\}\right], \quad i<j \\
& \overline{p_{i j, k}}=s_{(g(h)-1) / 2}, \quad i=j \\
& \overline{p_{i j, k}}=\Delta\left((g(h)-1)-\Delta^{-1}\left(\overline{p_{j i, k}}\right)\right), \quad i>j
\end{aligned}
$$$$
\text { where } p_{i j, c}^{g(h)}=\Delta\left(g(h) / 2+(g(h)(n-1) / 2)\left(\omega_{i}^{c}-\omega_{j}^{c}\right)\right) \text {. }
$$

Furthermore, based on the adjustment proposals, a group consensus reaching Algorithm 1 is constructed as shown in Algorithm 1.

Remark 10. Thresholds $\overline{G C I}$ provide a flexible option to control the decision process. Once thresholds $\overline{G C I}$ are specified, Step 4 is implemented to determine which experts need to adjust their opinion and then Step 5 gives a specific scheme to make adjustments. After expert opinion $P_{k}^{(t)}$ is adjusted, optimization model (13) is reused to determine the new experts' weights with those updated information. By iteratively adjusting the experts' opinion and weights, the consensus level gradually is improved.

3.3.3. A Step-by-Step Procedure of the GDM Model with IMGFLPRs. Below we shall provide a GDM model with IMGFLPRs based on mathematical programming. Assume that there are $n$ alternatives $x_{1}, x_{2}, \cdots, x_{n}$ and experts' weight $u=\left(u_{1}, u_{2}, \cdots, u_{m}\right)^{T}$ related to experts $e_{1}, e_{2}, \cdots, e_{m}$. $P_{k}(k=1,2, \cdots, m)$ indicates the 2 -tuple FLPRs given by experts $e_{1}, e_{2}, \cdots, e_{m}$ based on the given linguistic term sets $S^{g^{(1)}}, S^{g^{(2)}}, \cdots, S^{g(r)}$. The flow chart of proposed GDM model is illustrated by Figure 1, and its procedure is specifically shown as follows. 


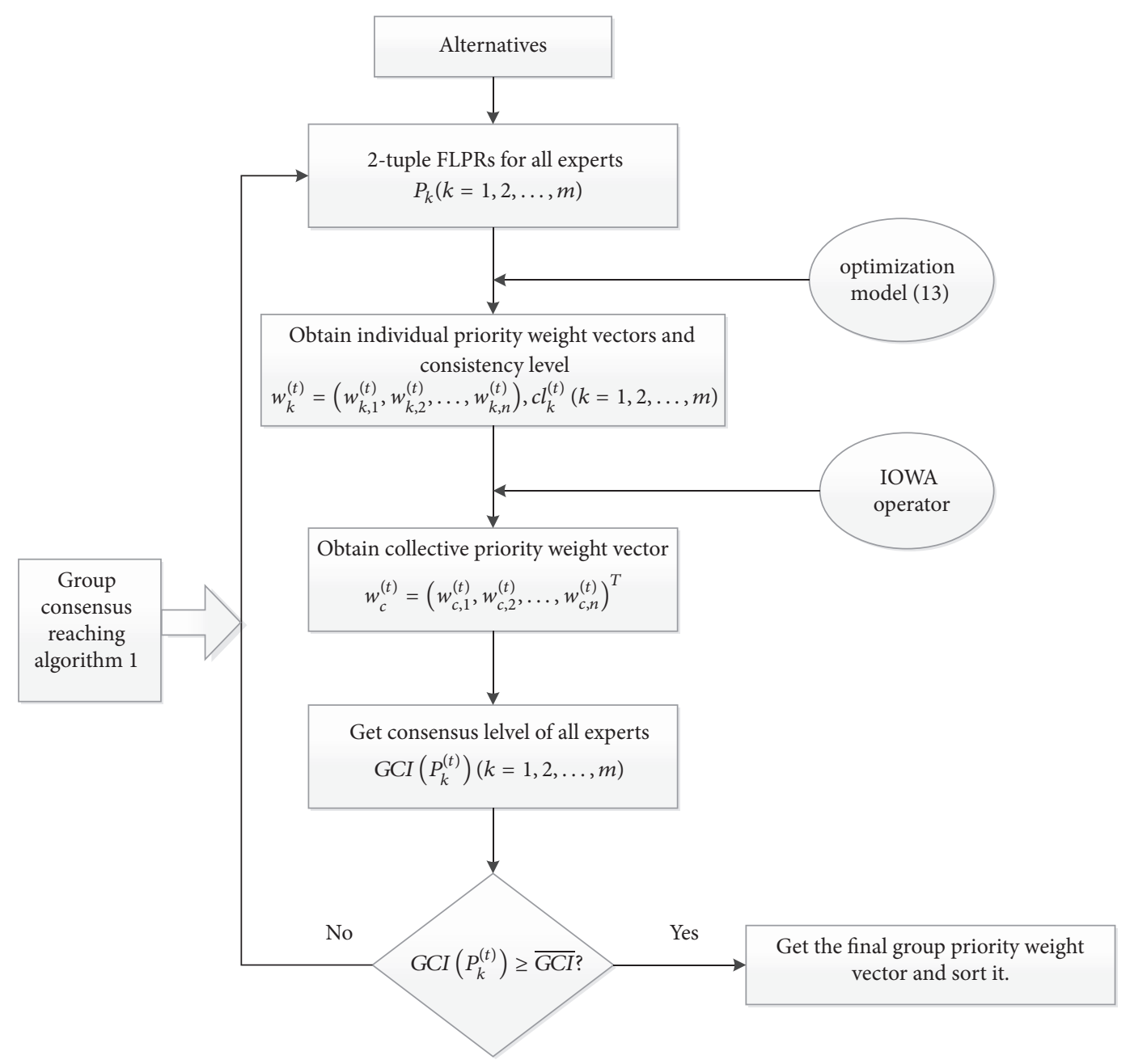

FIGURE 1: Procedure of the GDM model with incomplete multi-granular 2-tuple FLPRs.

Step 1. Every expert needs to provide only the most confident assessed linguistic terms between two alternatives by paired comparison method based on given linguistic scale sets $S^{g^{(1)}}, S^{g(2)}, \cdots, S^{g(r)}$ by means of their experience and expertise knowledge, where missing comparisons are denoted by " $x$ ".

Step 2. Obtain the individual priority weight vectors for all experts $e_{1}, e_{2}, \cdots, e_{m}$ by means of model (13), respectively.

Step 3. Fuse individual priority weight vectors to collective priority weight vector using IOWA operator.

Step 4. Achieve group consensus with satisfying index by means of Algorithm 1.

Step 5. Rank alternatives $A_{i}(i=1,2, \cdots, n)$ according to the final collective priority weight vector.

Step 6. End.

\section{Case Study}

In recent years, more and more disasters have taken place in the world. They have brought great influence and threat to people's lives [4], for example, China's Wenchuan Earthquake in 2008 and Japan's Earthquake in 2011. The arrangement of the disaster relief work is an important link, how to ensure the earthquake materials supplies in the shortest possible time, the highest security, and the best economic way to transport goods demand point is very important. Here we give four different emergency decisions of the scheduling:

$\left(x_{1}\right)$ Airdrop relief supplies

$\left(x_{2}\right)$ Repairing damaged roads and transporting relief supplies by car

$\left(x_{3}\right)$ Repairing damaged rail and rail transport

$\left(x_{4}\right)$ Transporting a large number of people on foot.

In order to choose the most suitable emergency rescue plan from the above four emergency rescue plans, in here, the emergency rescue alternatives $X=\left\{x_{1}, x_{2}, x_{3}, x_{4}\right\}$ will be evaluated by three experts $E=\left\{e_{1}, e_{2}, e_{3}\right\}$. The linguistic term sets used by experts $e_{1}, e_{2}, e_{3}$ are $S^{5}=\left\{s_{0}^{5}, s_{1}^{5}, \cdots, s_{4}^{5}\right\}$, $S^{7}=\left\{s_{0}^{7}, s_{1}^{7}, \cdots, s_{6}^{7}\right\}$, and $S^{9}=\left\{s_{0}^{9}, s_{1}^{9}, \cdots, s_{8}^{9}\right\}$, respectively. 
Step 1. Every expert gives his/her linguistic assessed values between every two alternatives by paired comparison method based on the given linguistic scale sets $S^{5}, S^{7}, S^{9}$, respectively. In here, the experts only give the most confident comparisons based on their experience and expertise knowledge, where missing comparisons are denoted by " $x$ ". Then, we obtain three incomplete multi-granular 2-tuple FLPRs $P_{k}(k=$ $1,2,3)$ with three experts $E=\left\{e_{1}, e_{2}, e_{3}\right\}$, respectively:

$$
\begin{gathered}
P_{1}=\left[\begin{array}{cccc}
\left(s_{2}^{5}, 0\right) & \left(s_{2}^{5}, 0\right) & \left(s_{3}^{5}, 0\right) & \left(s_{3}^{5}, 0\right) \\
\left(s_{2}^{5}, 0\right) & \left(s_{2}^{5}, 0\right) & x & \left(s_{3}^{5}, 0\right) \\
\left(s_{1}^{5}, 0\right) & x & \left(s_{2}^{5}, 0\right) & x \\
\left(s_{1}^{5}, 0\right) & \left(s_{1}^{5}, 0\right) & x & \left(s_{2}^{5}, 0\right)
\end{array}\right], \\
P_{2}=\left[\begin{array}{llll}
\left(s_{3}^{7}, 0\right) & \left(s_{2}^{7}, 0\right) & \left(s_{4}^{7}, 0\right) & \left(s_{3}^{7}, 0\right) \\
\left(s_{4}^{7}, 0\right) & \left(s_{3}^{7}, 0\right) & \left(s_{4}^{7}, 0\right) & \left(s_{4}^{7}, 0\right) \\
\left(s_{2}^{7}, 0\right) & \left(s_{2}^{7}, 0\right) & \left(s_{3}^{7}, 0\right) & \left(s_{2}^{7}, 0\right) \\
\left(s_{3}^{7}, 0\right) & \left(s_{2}^{7}, 0\right) & \left(s_{4}^{7}, 0\right) & \left(s_{3}^{7}, 0\right)
\end{array}\right], \\
P_{3}=\left[\begin{array}{cccc}
\left(s_{4}^{9}, 0\right) & \left(s_{3}^{9}, 0\right) & x & \left(s_{5}^{9}, 0\right) \\
\left(s_{5}^{9}, 0\right) & \left(s_{4}^{9}, 0\right) & \left(s_{5}^{9}, 0\right) & x \\
x & \left(s_{3}^{9}, 0\right) & \left(s_{4}^{9}, 0\right) & \left(s_{6}^{9}, 0\right) \\
\left(s_{3}^{9}, 0\right) & x & \left(s_{2}^{9}, 0\right) & \left(s_{4}^{9}, 0\right)
\end{array}\right] .
\end{gathered}
$$

Step 2. The individual priority weight vectors and consistency levels are obtained based on $P_{k}(k=1,2,3)$ by model (13) and (14):

$$
\begin{aligned}
& \omega_{1}=(0.3333,0.3333,0.1667,0.1667)^{T}, \\
& d_{34}^{-}=4,
\end{aligned}
$$

and $c l\left(P_{1}\right)=0.8333$;

$$
\begin{aligned}
& \omega_{2}=(0.25,0.3611,0.1389,0.25)^{T}, \\
& d_{23}^{+}=1,
\end{aligned}
$$

and $c l\left(P_{2}\right)=0.9722$;

$$
\omega_{3}=(0.2395,0.3438,0.2813,0.1354)^{T},
$$

$d_{12}^{-}=0.251$,

$d_{14}^{+}=0.2497$,

$d_{23}^{-}=0.2494$,

$$
\begin{aligned}
d_{34}^{-} & =0.2498, \\
\text { and } c l\left(P_{3}\right) & =0.9792
\end{aligned}
$$

Step 3 (group consensus reaching process). Since $c l\left(P_{1}\right)=$ 0.8333, $\operatorname{cl}\left(P_{2}\right)=0.9722, \operatorname{cl}\left(P_{3}\right)=0.9792$, we have $\sigma(1)=$ $3, \sigma(2)=2, \sigma(3)=1$. Then, we use the function $Q(x)=x^{0.9}$ proposed by $\mathrm{Xu}$ et al. [35] in IOWA operator to determine experts' weights as follows:

$$
\begin{aligned}
& u_{3}=Q\left(\frac{0.9792}{\sum_{i=1}^{3} c l_{i}}\right)=Q(0.3516)=0.3903 ; \\
& u_{2}=Q\left(\frac{0.9792+0.9722}{\sum_{i=1}^{3} c l_{i}}\right)-Q(0.3516)=0.3359 \\
& u_{1}=1-0.3903-0.3359=0.2738 .
\end{aligned}
$$

On the basis of the original experts' weight vector $u^{(0)}=$ $(0.2738,0.3359,0.3903)^{T}$, the original collective preference vector is $\omega_{c}^{0}=(0.2687,0.3467,0.2021,0.1825)^{T}$ and consensus indices for each expert are as follows:

$$
\begin{aligned}
& \operatorname{GCI}\left(e_{1}\right)=0.9617 \\
& \operatorname{GCI}\left(e_{2}\right)=0.9523 \\
& \operatorname{GCI}\left(e_{3}\right)=0.9516 .
\end{aligned}
$$

According to the practical problems, the experts agree to set up $\overline{G C I}=0.98$. Then Algorithm 1 is applied to adjust the original FLPRs. Since $G C I\left(e_{k}\right)<\overline{G C I}(k=1,2,3)$, we need to find the position of elements $d_{i_{\tau} j_{\tau}, k}^{(0)}(k=1,2,3)$, where $d_{i_{\tau} j_{\tau}, k}^{(t)}=$ $\max _{(i, j)}\left|\Delta^{-1}\left(p_{i j, k}^{(t)}\right)-\Delta^{-1}\left(p_{i j, \mathrm{c}}^{(t)}\right)\right|$.

With regard to $P_{1}^{(0)}$, as $d_{13,1}^{(0)}=d_{31,1}^{(0)}=\max _{(i, j)} \mid \Delta^{-1}\left(p_{i j, 1}^{(0)}\right)-$ $\Delta^{-1}\left(p_{i j, \mathrm{c}}^{(0)}\right) \mid=0.6, d_{13,1}^{(0)}, d_{31,1}^{(0)}$ need to be adjusted to $d_{13,1}^{(0)}=$ $\left(s_{3},-0.5\right), d_{31,1}^{(0)}=\left(s_{1},-0.5\right)$ according to $S U G_{1}^{(1)}$.

$$
P_{1}^{(1)}=\left[\begin{array}{cccc}
\left(s_{2}^{5}, 0\right) & \left(s_{2}^{5}, 0\right) & \left(\mathbf{s}_{3}^{\mathbf{5}},-\mathbf{0 . 5}\right) & \left(s_{3}^{5}, 0\right) \\
\left(s_{2}^{5}, 0\right) & \left(s_{2}^{5}, 0\right) & x & \left(s_{3}^{5}, 0\right) \\
\left(\mathbf{s}_{2}^{\mathbf{5}},-\mathbf{0 . 5}\right) & x & \left(s_{2}^{5}, 0\right) & x \\
\left(s_{1}^{5}, 0\right) & \left(s_{1}^{5}, 0\right) & x & \left(s_{2}^{5}, 0\right)
\end{array}\right]
$$

where

$$
S U G_{1}^{(1)}=\left[\begin{array}{cccc}
{\left[\left(s_{2}^{5}, 0\right),\left(s_{2}^{5}, 0\right)\right]} & {\left[\left(s_{2}^{5},-0.47\right),\left(s_{2}^{5}, 0\right)\right]} & {\left[\left(s_{2}^{5}, 0.4\right),\left(s_{3}^{5}, 0\right)\right]} & {\left[\left(s_{3}^{5},-0.48\right),\left(s_{3}^{5}, 0\right)\right]} \\
{\left[\left(s_{2}^{5}, 0\right),\left(s_{2}^{5}, 0.47\right)\right]} & {\left[\left(s_{2}^{5}, 0\right),\left(s_{2}^{5}, 0\right)\right]} & x & {\left[\left(s_{3}^{5}, 0\right),\left(s_{3}^{5}, 0\right)\right]} \\
{\left[\left(s_{1}^{5}, 0\right),\left(s_{2}^{5},-0.4\right)\right]} & x & {\left[\left(s_{2}^{5}, 0\right),\left(s_{2}^{5}, 0\right)\right]} & x \\
{\left[\left(s_{1}^{5}, 0\right),\left(s_{1}^{5}, 0.48\right)\right]} & {\left[\left(s_{1}^{5}, 0\right),\left(s_{1}^{5}, 0\right)\right]} & x & {\left[\left(s_{2}^{5}, 0\right),\left(s_{2}^{5}, 0\right)\right]}
\end{array}\right]
$$

with $\operatorname{sug} g_{i j}^{(1)}=\left[\min \left(p_{i j}^{(1)}, p_{i j}^{(1, c)}\right), \max \left(p_{i j}^{(1)}, p_{i j}^{(1, c)}\right)\right]$. 
TABLE 1: To compare the situation of FLPRs after adjusting for three experts.

\begin{tabular}{|c|c|c|c|c|}
\hline Experts & & before the adjustment & & after the adjustment \\
\hline \multirow{4}{*}{ expert $e_{1}$} & & 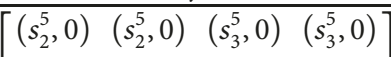 & \multirow{4}{*}{$P_{1}^{(2)}=$} & $\begin{array}{llll}\left(s_{2}^{5}, 0\right) & \left(s_{2}^{5}, 0\right) & \left(\mathbf{s}_{3}^{5},-0.5\right) & \left(\mathbf{s}_{3}^{5},-0.4\right)\end{array}$ \\
\hline & & $\left(s_{2}^{5}, 0\right) \quad\left(s_{2}^{5}, 0\right) \quad x \quad\left(s_{3}^{5}, 0\right)$ & & $\left(s_{2}^{5}, 0\right) \quad\left(s_{2}^{5}, 0\right) \quad x$ \\
\hline & $F_{1}-$ & $\left(s_{1}^{5}, 0\right) \quad x \quad\left(s_{2}^{5}, 0\right) \quad x$ & & $\left(\mathrm{~s}_{2}^{5},-0.5\right) \quad x$ \\
\hline & & $\left.\left(s_{1}^{5}, 0\right)\left(s_{1}^{5}, 0\right) \quad x \quad\left(s_{2}^{5}, 0\right)\right]$ & & $\left(s_{1}^{5}, 0.4\right) \quad\left(s_{1}^{5}, 0\right)$ \\
\hline \multirow{4}{*}{ expert $e_{2}$} & \multirow{4}{*}{$P_{2}=$} & $\begin{array}{llll}\left(s_{3}^{7}, 0\right) & \left(s_{2}^{7}, 0\right) & \left(s_{4}^{7}, 0\right) & \left(s_{3}^{7}, 0\right)\end{array}$ & \multirow{4}{*}{$P_{2}^{(2)}=$} & {$\left[\begin{array}{llll}\left(s_{3}^{7}, 0\right) & \left(s_{2}^{7}, 0\right) & \left(s_{4}^{7}, 0\right) & \left(\mathbf{s}_{\mathbf{4}}^{7},-\mathbf{0 . 4}\right)\end{array}\right.$} \\
\hline & & $\left(s_{4}^{7}, 0\right) \quad\left(s_{3}^{7}, 0\right) \quad\left(s_{4}^{7}, 0\right) \quad\left(s_{4}^{7}, 0\right)$ & & $\left(s_{4}^{7}, 0\right) \quad\left(s_{3}^{7}, 0\right) \quad\left(s_{4}^{7}, 0\right) \quad\left(s_{4}^{7}, 0\right)$ \\
\hline & & $\left(s_{2}^{7}, 0\right) \quad\left(s_{2}^{7}, 0\right) \quad\left(s_{3}^{7}, 0\right) \quad\left(s_{2}^{7}, 0\right)$ & & $\left(s_{2}^{7}, 0\right) \quad\left(s_{2}^{7}, 0\right) \quad\left(s_{3}^{7}, 0\right) \quad\left(\mathbf{s}_{3}^{7}, \mathbf{0}\right)$ \\
\hline & & $\left(\begin{array}{llll}\left(s_{3}^{7}, 0\right) & \left(s_{2}^{7}, 0\right) & \left(s_{4}^{7}, 0\right) & \left(s_{3}^{7}, 0\right)\end{array}\right.$ & & {$\left[\begin{array}{llll}\left(\mathbf{s}_{2}^{7}, \mathbf{0 . 4}\right) & \left(s_{2}^{7}, 0\right) & \left(\mathrm{s}_{3}^{7}, \mathbf{0}\right) & \left(s_{3}^{7}, 0\right)\end{array}\right.$} \\
\hline \multirow{4}{*}{ expert $e_{3}$} & \multirow{4}{*}{$P_{3}=$} & {$\left[\begin{array}{llll}\left(s_{4}^{9}, 0\right) & \left(s_{3}^{9}, 0\right) \quad x \quad\left(s_{5}^{9}, 0\right)\end{array}\right]$} & \multirow{4}{*}{$P_{3}^{(1)}=$} & $\left(s_{4}^{9}, 0\right) \quad\left(s_{3}^{9}, 0\right) \quad x \quad\left(s_{5}^{9}, 0\right)$ \\
\hline & & $\left(s_{5}^{9}, 0\right) \quad\left(s_{4}^{9}, 0\right) \quad\left(s_{5}^{9}, 0\right) \quad x$ & & $=\left(\begin{array}{llll}\left(s_{5}^{9}, 0\right) & \left(s_{4}^{9}, 0\right) & \left(s_{5}^{9}, 0\right) \quad x\end{array}\right.$ \\
\hline & & $\left(s_{3}^{9}, 0\right) \quad\left(s_{4}^{9}, 0\right) \quad\left(s_{6}^{9}, 0\right)$ & & $\begin{array}{llll}x & \left(s_{3}^{9}, 0\right) & \left(s_{4}^{9}, 0\right) & \left(\mathbf{s}_{5}^{9}, \mathbf{0}\right)\end{array}$ \\
\hline & & $\left.\left(s_{2}^{9}, 0\right)\left(s_{4}^{9}, 0\right)\right\rfloor$ & & $\left.\left(\mathbf{s}_{3}^{9}, \mathbf{0}\right)\left(s_{4}^{9}, 0\right)\right]$ \\
\hline
\end{tabular}

With regard to $P_{2}^{(0)}$ and $P_{3}^{(0)}$, the same procedures are implemented to obtain the adjusted FLPRs $P_{2}^{(1)}, P_{3}^{(1)}$ according to the $S U G_{2}^{(1)}, S U G_{3}^{(1)}$ as follows:

$$
P_{2}^{(1)}=\left[\begin{array}{cccc}
\left(s_{3}^{7}, 0\right) & \left(s_{2}^{7}, 0\right) & \left(s_{4}^{7}, 0\right) & \left(s_{3}^{7}, 0\right) \\
\left(s_{4}^{7}, 0\right) & \left(s_{3}^{7}, 0\right) & \left(s_{4}^{7}, 0\right) & \left(s_{4}^{7}, 0\right) \\
\left(s_{2}^{7}, 0\right) & \left(s_{2}^{7}, 0\right) & \left(s_{3}^{7}, 0\right) & \left(\mathbf{s}_{3}^{7}, 0\right) \\
\left(s_{3}^{7}, 0\right) & \left(s_{2}^{7}, 0\right) & \left(\mathbf{s}_{3}^{7}, 0\right) & \left(s_{3}^{7}, 0\right)
\end{array}\right]
$$

where

$$
\begin{aligned}
S U G_{2}^{(1)}= & {\left[\begin{array}{cccc}
{\left[\left(s_{3}^{7}, 0\right),\left(s_{3}^{7}, 0\right)\right]} & {\left[\left(s_{2}^{7}, 0\right),\left(s_{2}^{7}, 0.3\right)\right]} & {\left[\left(s_{4}^{7},-0.4\right),\left(s_{4}^{7}, 0\right)\right]} & {\left[\left(s_{3}^{7}, 0\right),\left(s_{4}^{7},-0.22\right)\right]} \\
{\left[\left(s_{4}^{7},-0.3\right),\left(s_{4}^{7}, 0\right)\right]} & {\left[\left(s_{3}^{7}, 0\right),\left(s_{3}^{7}, 0\right)\right]} & {\left[\left(s_{4}^{7}, 0\right),\left(s_{4}^{7}, 0.3\right)\right]} & {\left[\left(s_{4}^{7}, 0\right),\left(s_{4}^{7}, 0.48\right)\right]} \\
{\left[\left(s_{2}^{7}, 0\right),\left(s_{2}^{7}, 0.4\right)\right]} & {\left[\left(s_{2}^{7},-0.3\right),\left(s_{2}^{7}, 0\right)\right]} & {\left[\left(s_{3}^{7}, 0\right),\left(s_{3}^{7}, 0\right)\right]} & {\left[\left(s_{2}^{7}, 0\right),\left(s_{3}^{7}, 0.18\right)\right]} \\
{\left[\left(s_{2}^{7}, 0.22\right),\left(s_{3}^{7}, 0\right)\right]} & {\left[\left(s_{2}^{7},-0.48\right),\left(s_{2}^{7}, 0\right)\right]} & {\left[\left(s_{3}^{7},-0.18\right),\left(s_{4}^{7}, 0\right)\right]} & {\left[\left(s_{3}^{7}, 0\right),\left(s_{3}^{7}, 0\right)\right]}
\end{array}\right] . } \\
S U G_{3}^{(1)}= & {\left[\begin{array}{cccc}
{\left[\left(s_{4}^{9}, 0\right),\left(s_{4}^{9}, 0\right)\right]} & {\left[\left(s_{3}^{9}, 0\right),\left(s_{3}^{9}, 0.06\right)\right]} & x & {\left[\left(s_{5}^{9}, 0\right),\left(s_{5}^{9}, 0.03\right)\right]} \\
{\left[\left(s_{5}^{9},-0.06\right),\left(s_{5}^{9}, 0\right)\right]} & {\left[\left(s_{4}^{9}, 0\right),\left(s_{4}^{9}, 0\right)\right]} & {\left[\left(s_{5}^{9}, 0\right),\left(s_{6}^{9},-0.26\right)\right]} & x \\
x & {\left[\left(s_{2}^{9}, 0.26\right),\left(s_{3}^{9}, 0\right)\right]} & {\left[\left(s_{4}^{9}, 0\right),\left(s_{4}^{9}, 0\right)\right]} & {\left[\left(s_{4}^{9}, 0.24\right),\left(s_{6}^{9}, 0\right)\right]} \\
x & {\left[\left(s_{2}^{9}, 0\right),\left(s_{4}^{9},-0.24\right)\right]} & {\left[\left(s_{4}^{9}, 0\right),\left(s_{4}^{9}, 0\right)\right]}
\end{array}\right] }
\end{aligned}
$$

Let $t=1$, then go to Step 2 .

Going through 2 rounds of adjustment, Algorithm 1 is terminated. On the whole, $e_{1}, e_{2}$, and $e_{3}$ adjust their FLPRs 2,2 , and 1 times, respectively. In addition, the final group consensus index of every expert and final collective priority weight vector are as follows:

$$
\begin{aligned}
& \operatorname{GCI}\left(P_{1}^{(2)}\right)=0.9857 \\
& \operatorname{GCI}\left(P_{2}^{(2)}\right)=0.9839
\end{aligned}
$$

$$
\operatorname{GCI}\left(P_{3}^{(1)}\right)=0.9814
$$

$w^{*}=w_{c}^{(2)}=(0.2714,0.3235,0.2246,0.1805)^{T}$.

Furthermore, the adjustment variations of FLPRs for three experts are shown in Table 1.

Step 4. Rank alternatives $A_{i}(i=1,2,3,4)$ based on the final priority weight vector 
TABLE 2: Contrast between our method and existing related study.

\begin{tabular}{lcccc}
\hline Methods & $\begin{array}{c}\text { Handling method for } \\
\text { IMGPLPR }\end{array}$ & $\begin{array}{c}\text { Dynamic adjustment } \\
\text { of experts weights }\end{array}$ & Consensus & Ranking \\
\hline $\begin{array}{l}\text { The proposed } \\
\text { method }\end{array}$ & Optimization model & Yes & Yes & $A_{2}>A_{1}>A_{3}>A_{4}$ \\
Xu et al [4] & Filling method & No & No & $A_{2}>A_{1}>A_{4}>A_{3}$ \\
\hline
\end{tabular}

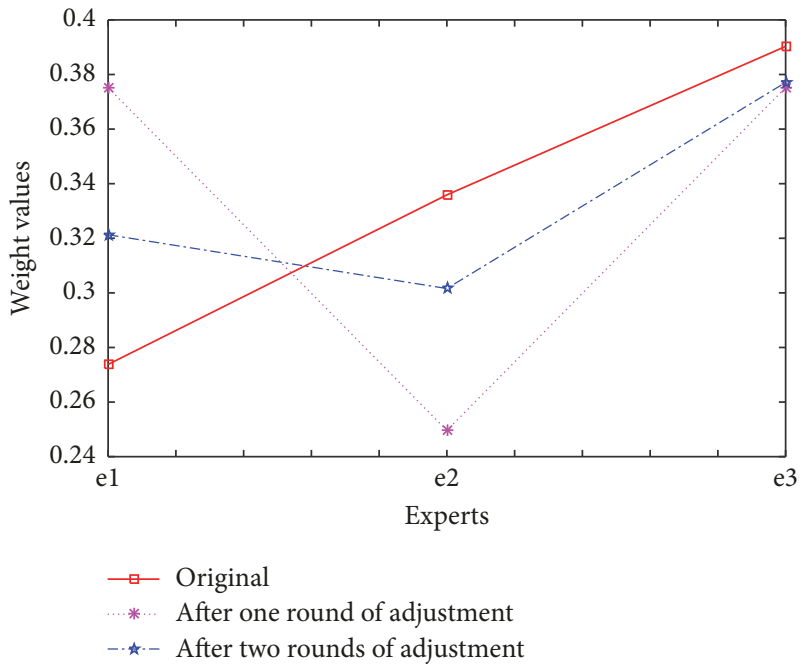

FIGURE 2: Adjust dynamically the weight of the experts in iterative process.

According to the final priority weight vector $w^{*}=$ $(0.2714,0.3235,0.2246,0.1805)^{T}$, the ranking of alternatives is $A_{2}>A_{1}>A_{3}>A_{4}$; i.e., repairing damaged roads and transporting relief supplies by car are the best choice.

\section{Discussion}

As mentioned in introduction, there are two related studies $[4,8]$ to deal with IMGFLPRs in group decision-making. In this section, we carry out a comparison of our suggested method with previous related research $[4,8]$. First, the dynamic regulation for experts' weights in iterative process according to adjusted information quality is intuitively shown in Figure 2. By means of Figure 2, weight of experts is changed according to their information quality. Second, the differences between the method proposed in this paper and the above-mentioned study [4] are summarized in Table 2. From Table 2, it can be seen that the using above two strategies gets the same optimal rescue plan $A_{2}$. While the sorting results for $A_{3}$ and $A_{4}$ using above two strategies are different, the reason for different ranking for $A_{3}$ and $A_{4}$ may be that the method [4] has not considered the consensus reaching in GDM.

In short, the main contributions of the paper can be summed up as follows:

(i) A consensus reaching algorithm is constructed based on direct consensus framework for IMGFLPRs in
GDM, while existing related studies $[4,8]$ does not take into account this situation.

(ii) Previous related research $[4,8]$ was needed to fill the incomplete elements and revert to uniform granularity, while our proposed optimization model to deal with IMGFLPR needed not to carry out the two steps above and then obtained directly the priority weight vector of alternatives, which avoids information loss and reduces the computation complexity.

(iii) A dynamic adjustment procedure of experts' weight is proposed according to the quality of adjusted information.

\section{Conclusions}

In this paper, we proposed a novel GDM method with incomplete multi-granular 2-tuple FLPRs based on mathematical programming. A consensus reaching algorithm based on the direct approach is constructed, which makes decision results more believable. And most of all, the uniform language granularity and estimating unknown elements are avoided by our proposed mathematical programming to reduce computation greatly. Then, a step-by-step GDM procedure based on the group consensus reaching algorithm has been concluded. Following the procedure, an emergency decision problem is worked out by means of the proposed model.

In future, it is also interesting to analyze GDM problems with incomplete 2-tuple FLPRs based on multi-granular unbalanced linguistic terms [38]. Besides, the proposed model also can be applied to different problems such as Traditional Chinese Medicine decision support [39-41] and Decision Support System [42].

\section{Data Availability}

The data used to support the findings of this study are available from the corresponding author upon request.

\section{Conflicts of Interest}

The authors declare that there are no conflicts of interest regarding the publication of this paper.

\section{Acknowledgments}

This research was supported in part by grants from the National Social Science Foundation of China (\#16BGL181) and the Natural Science Foundation of Shandong Province (ZR201702130105). 


\section{References}

[1] L. A. Zadeh, "The concept of a linguistic variable and its application to approximate reasoning I," Information Sciences, vol. 8, pp. 199-249, 1975.

[2] E. Herrera-Viedma, L. Martínez, F. Mata, and F. Chiclana, "A consensus support system model for group decision-making problems with multigranular linguistic preference relations," IEEE Transactions on Fuzzy Systems, vol. 13, no. 5, pp. 644-658, 2005.

[3] J. A. Morente-Molinera, I. J. Pérez, M. R. Ureña, and E. HerreraViedma, "On multi-granular fuzzy linguistic modeling in group decision making problems: A systematic review and future trends," Knowledge-Based Systems, vol. 74, pp. 49-60, 2015.

[4] Y. Xu, F. Ma, W. Xu, and H. Wang, "An incomplete multigranular linguistic model and its application in emergency decision of unconventional outburst incidents," Journal of Intelligent \& Fuzzy Systems: Applications in Engineering and Technology, vol. 29, no. 2, pp. 619-633, 2015.

[5] Z. Xu and H. Wang, "Managing multi-granularity linguistic information in qualitative group decision making: an overview," Granular Computing, vol. 1, no. 1, pp. 21-35, 2016.

[6] Z. Zhang, C. Guo, and L. Martinez, "Managing multigranular linguistic distribution assessments in large-scale multiattribute group decision making," IEEE Transactions on Systems, Man, and Cybernetics: Systems, vol. 47, no. 11, pp. 3063-3076, 2017.

[7] H. Zhang, Y. Dong, and X. Chen, "The 2-rank consensus reaching model in the multigranular linguistic multiple-attribute group decision-making," IEEE Transactions on Systems, Man, and Cybernetics: Systems, pp. 1-15, 2017.

[8] X. Zhang, H. Zhang, and J. Wang, "Discussing incomplete 2-tuple fuzzy linguistic preference relations in multi-granular linguistic MCGDM with unknown weight information," Soft Computing, 2017.

[9] Y. Song and G. Li, "A large-scale group decision-making with incomplete multi-granular probabilistic linguistic term sets and its application in sustainable supplier selection," Journal of the Operational Research Society, pp. 1-15, 2018.

[10] T. L. Saaty, The Analytic Hierarchy Process, McGraw-Hill, New York, NY, USA, 1980.

[11] T. Tanino, "Fuzzy preference orderings in group decision making," Fuzzy Sets and Systems, vol. 12, no. 2, pp. 117-131, 1984.

[12] Z. S. Xu, "Deviation measures of linguistic preference relations in group decision making," Omega, vol. 33, no. 3, pp. 249-254, 2005.

[13] R. Ureña, F. Chiclana, J. A. Morente-Molinera, and E. HerreraViedma, "Managing incomplete preference relations in decision making: a review and future trends," Information Sciences, vol. 302, no. 1, pp. 14-32, 2015.

[14] Z. Xu, "Incomplete linguistic preference relations and their fusion," Information Fusion, vol. 7, no. 3, pp. 331-337, 2006.

[15] E. Herrera-Viedma, S. Alonso, F. Chiclana, and F. Herrera, "A consensus model for group decision making with incomplete fuzzy preference relations," IEEE Transactions on Fuzzy Systems, vol. 15, no. 5, pp. 863-877, 2007.

[16] D. Ergu, G. Kou, Y. Peng, and M. Zhang, "Estimating the missing values for the incomplete decision matrix and consistency optimization in emergency management," Applied Mathematical Modelling: Simulation and Computation for Engineering and Environmental Systems, vol. 40, no. 1, pp. 254-267, 2016.

[17] Y. J. Xu, L. Chen, R. M. Rodríguez, F. Herrera, and H. M. Wang, "Deriving the priority weights from incomplete hesitant fuzzy preference relations in group decision making," KnowledgeBased Systems, vol. 99, pp. 71-78, 2016.

[18] F. J. Cabrerizo, I. J. Pérez, and E. Herrera-Viedma, "Managing the consensus in group decision making in an unbalanced fuzzy linguistic context with incomplete information," KnowledgeBased Systems, vol. 23, no. 2, pp. 169-181, 2010.

[19] Z. Wu and J. Xu, "Consensus reaching models of linguistic preference relations based on distance functions," Soft Computing, vol. 16, no. 4, pp. 577-589, 2012.

[20] Y. Xu, K. W. Li, and H. Wang, "Distance-based consensus models for fuzzy and multiplicative preference relations," Information Sciences, vol. 253, pp. 56-73, 2013.

[21] I. J. Pérez, F. J. Cabrerizo, S. Alonso, and E. Herrera-Viedma, "A new consensus model for group decision making problems with non-homogeneous experts," IEEE Transactions on Systems, Man, and Cybernetics: Systems, vol. 44, no. 4, pp. 494-498, 2014.

[22] Y. Xu, F. Ma, F. Tao, and H. Wang, "Some methods to deal with unacceptable incomplete 2-tuple fuzzy linguistic preference relations in group decision making," Knowledge-Based Systems, vol. 56, pp. 179-190, 2014.

[23] Y. C. Dong, Z.-P. Fan, and S. Yu, "Consensus building in a local context for the AHP-GDM with the individual numerical scale and prioritization method," IEEE Transactions on Fuzzy Systems, vol. 23, no. 2, pp. 354-368, 2015.

[24] H. Liao, Z. Xu, X.-J. Zeng, and D.-L. Xu, "An enhanced consensus reaching process in group decision making with intuitionistic fuzzy preference relations," Information Sciences, vol. 329, pp. 274-286, 2016.

[25] G. Li, G. Kou, and Y. Peng, "A Group decision making model for integrating heterogeneous information," IEEE Transactions on Systems, Man, and Cybernetics: Systems, vol. 48, no. 6, pp. 982-992, 2018.

[26] M. Zhao, X.-Y. Ma, and D.-W. Wei, "A method considering and adjusting individual consistency and group consensus for group decision making with incomplete linguistic preference relations," Applied Soft Computing, vol. 54, pp. 322-346, 2017.

[27] W. Zhang, Y. Xu, and $\mathrm{H}$. Wang, "A consensus reaching model for 2-tuple linguistic multiple attribute group decision making with incomplete weight information," International Journal of Systems Science, vol. 47, no. 2, pp. 389-405, 2016.

[28] F. Herrera and L. Martínez, "A 2-tuple fuzzy linguistic representation model for computing with words," IEEE Transactions on Fuzzy Systems, vol. 8, no. 6, pp. 746-752, 2000.

[29] S. Alonso, F. J. Cabrerizo, F. Chiclana, F. Herrera, and E. Herrera-Viedma, "Group decision making with incomplete fuzzy linguistic preference relations," International Journal of Intelligent Systems, vol. 24, no. 2, pp. 201-222, 2009.

[30] Y. M. Song and J. Hu, "A group decision-making model based on incomplete comparative expressions with hesitant linguistic terms," Applied Soft Computing, vol. 59, pp. 174-181, 2017.

[31] Y. Xu, Q. Da, and H. Wang, "A note on group decisionmaking procedure based on incomplete reciprocal relations," Soft Computing, vol. 15, no. 7, pp. 1289-1300, 2011.

[32] Y. Xu, K. W. Li, and H. Wang, "Consistency test and weight generation for additive interval fuzzy preference relations," Soft Computing, vol. 18, no. 8, pp. 1499-1513, 2014.

[33] J. Kacprzyk and M. Fedrizzi, "A "soft" measure of consensus in the setting of partial (fuzzy) preferences," European Journal of Operational Research, vol. 34, no. 3, pp. 316-325, 1988.

[34] E. Herrera-Viedma, F. J. Cabrerizo, J. Kacprzyk, and W. Pedrycz, "A review of soft consensus models in a fuzzy environment," Information Fusion, vol. 17, no. 1, pp. 4-13, 2014. 
[35] Y. Xu, F. J. Cabrerizo, and E. Herrera-Viedma, "A consensus model for hesitant fuzzy preference relations and its application in water allocation management," Applied Soft Computing, vol. 58, pp. 265-284, 2017.

[36] Y.-C. Dong and H.-J. Zhang, "Multiperson decision making with different preference representation structures: a direct consensus framework and its properties," Knowledge-Based Systems, vol. 58, pp. 45-57, 2014.

[37] H. Zhang, Y. Dong, and E. Herrera-Viedma, "Consensus building for the heterogeneous large-scale GDM with the individual concerns and satisfactions," IEEE Transactions on Fuzzy Systems, vol. 26, no. 2, pp. 884-898, 2018.

[38] Y. Dong, C.-C. Li, Y. Xu, and X. Gu, "Consensus-based group decision making under multi-granular unbalanced 2-tuple linguistic preference relations," Group Decision and Negotiation, vol. 24, no. 2, pp. 217-242, 2014.

[39] F. Yuan, H. Liu, S.-Q. Chen, and L. Xu, "A clustering method of Chinese medicine prescriptions based on modified firefly algorithm," Chinese Journal of Integrative Medicine, vol. 22, no. 12, pp. 941-946, 2016.

[40] Y. M. Song, J. Hu, and F. Schwenker, "Vector similarity measures of hesitant fuzzy linguistic term sets and their applications," PLoS ONE, vol. 12, no. 12, Article ID e0189579, 2017.

[41] Y. M. Song and G. X. Li, "Handling group decision-making model with incomplete hesitant fuzzy preference relations and its application in medical decision," Soft Computing, 2018.

[42] J. A. Morente-Molinera, R. Wikström, E. Herrera-Viedma, and C. Carlsson, "A linguistic mobile Decision Support System based on fuzzy ontology to facilitate knowledge mobilization," Decision Support Systems, vol. 81, pp. 66-75, 2016. 


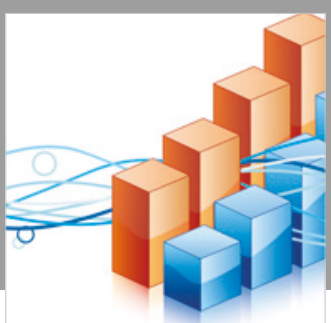

Advances in

Operations Research

\section{-n-m}
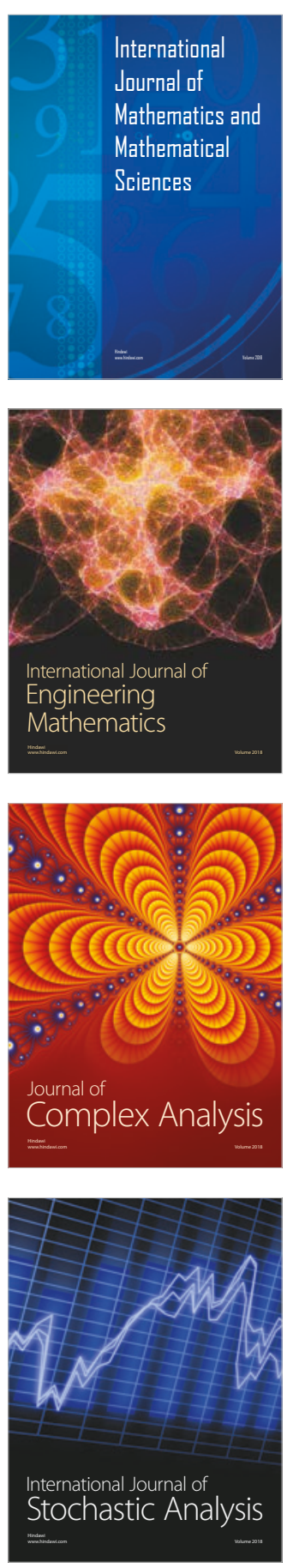
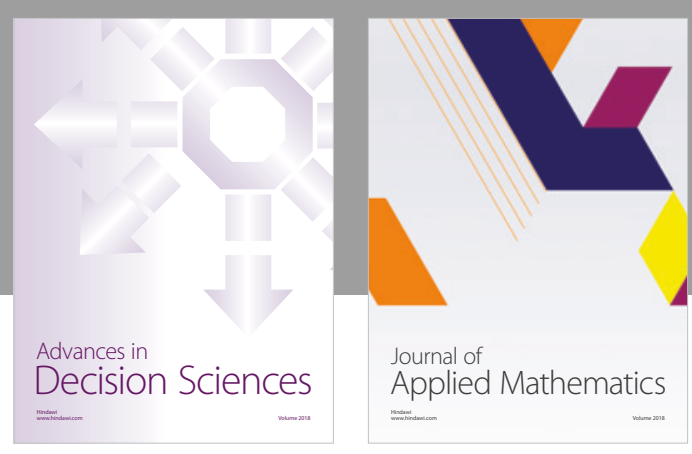

Journal of

Applied Mathematics
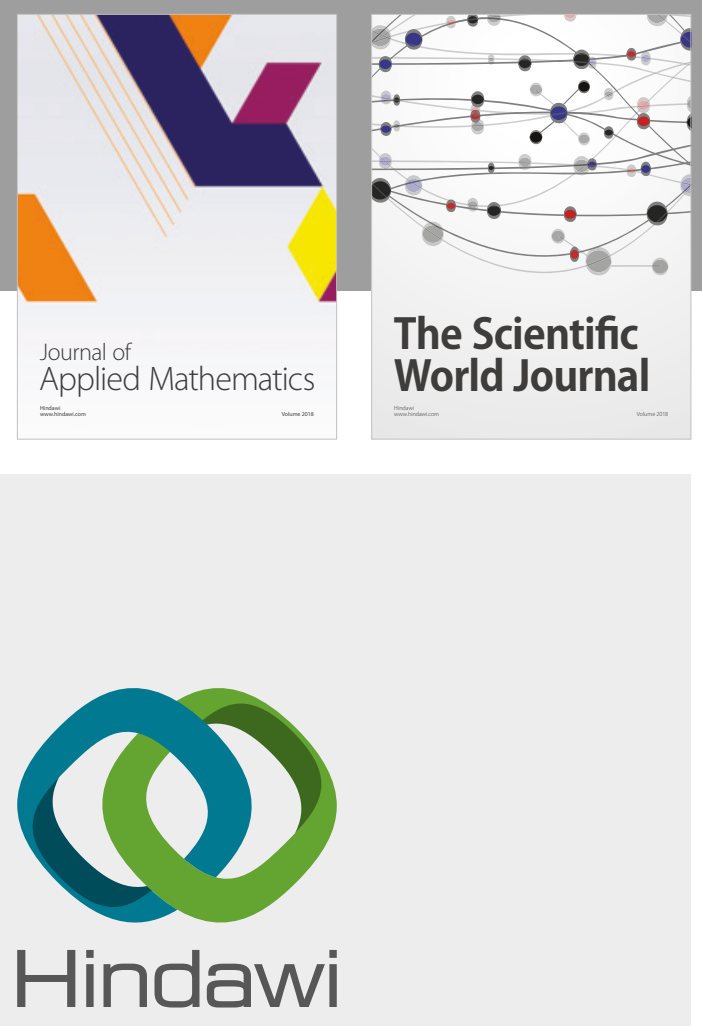

Submit your manuscripts at

www.hindawi.com

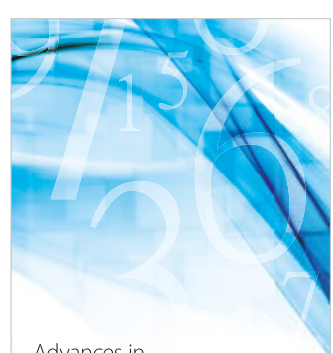

Advances in
Numerical Analysis
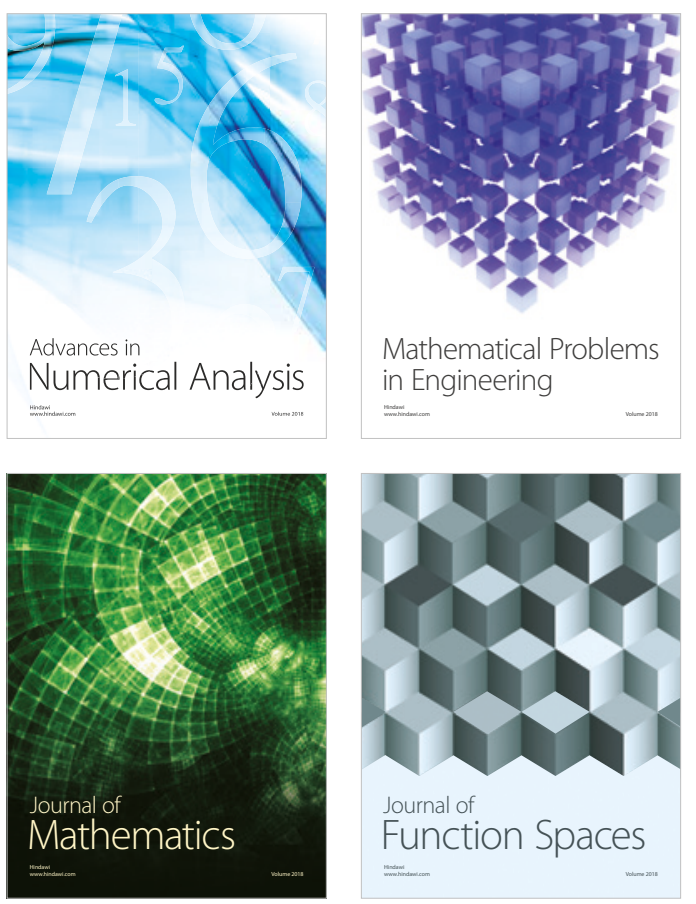

Mathematical Problems in Engineering

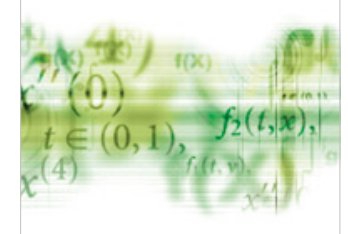

International Journal of

Differential Equations

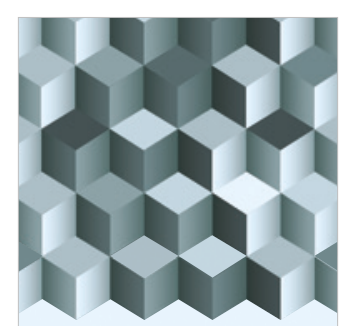

Journal of

Function Spaces

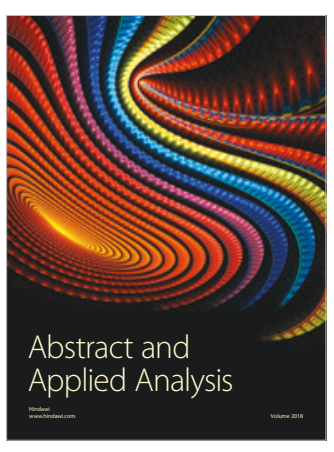

The Scientific

World Journal

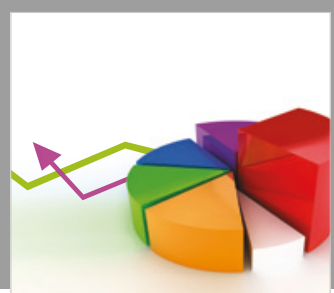

Journal of

Probability and Statistics
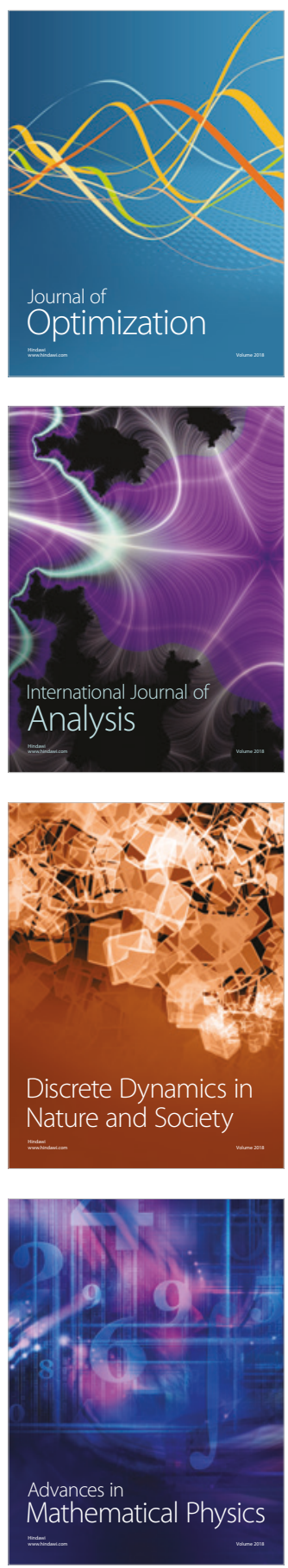